\title{
POR UMA ABORDAGEM COMPREENSIVA DA REDUPLICAÇÃO NO PORTUGUÊS DO BRASIL
}

\author{
Carlos Alexandre GONÇALVES (UFRJ/CNPq/Faperj) \\ Luciana de Albuquerque Daltio VIALLI (IFRJ)
}

\begin{abstract}
RESUMO: Neste texto, pretendemos mostrar que a reduplicação é um processo de formação de palavras de uso bem abrangente no português brasileiro. Observando em que situações o fenômeno se manifesta, procuramos diferenciar repetição de reduplicação, além de fornecer uma descrição adequada (formal e semântica) para cada padrão de reduplicação existente em português: (a) a composição $\mathrm{V}_{\mathrm{i}} \mathrm{V}_{\mathrm{i}}$ ("puxa-puxa', "doce"), (b) a sufixação intensiva ("chororô', "choro excessivo") e (c) a prefixação reduplicativa em nomes de parentesco ('vovó'), hipocorísticos ('Dedé', a partir do antropônimo 'André') e na interação pelo baby-talk ('neneca', redução afetiva de 'boneca').

PALAVRAS-CHAVE: Morfologia; Formação de Palavras; Reduplicação; Afixação.
\end{abstract}

\section{FOR A COMPREHENSIVE APPROACH OF REDUPLICATION IN BRAZILIAN PORTUGUESE}

\begin{abstract}
In this paper, we intend to show that reduplication is a word-formation process extremely productive in Brazilian Portuguese (BP). Observing in what situations the phenomenon manifests itself, we try to differentiate reduplication of repetition, providing an adequate description (formal and semantic) for each pattern of reduplication in BP: (a) the $\mathrm{V}_{\mathrm{i}} \mathrm{V}_{\mathrm{i}}$ compounding ("puxa-puxa', "toffee"), (b) intensive suffixation ("chororô', "excessive cry") and (c) the reduplicative prefixing in kinship names ('vovó', "grandma"), truncation names ('Dedé', affective reference of the anthroponym 'André') and in the interaction called baby-talk ('neneca', affective reduction of 'boneca', "doll"). KEYWORDS: Morphology;Word-formation; Reduplication; Affixation.
\end{abstract}

\section{INTRODUÇÃO}

Neste texto, pretendemos mostrar que a reduplicação é um processo de formação de palavras de uso bem abrangente no português brasileiro. Observando em que situações o fenômeno se manifesta, procuramos, em primeiro lugar, diferenciar repetição de reduplicação, além de fornecer uma descrição adequada (formal e semântica) para cada padrão de reduplicação que identificamos em português: (a) a composição $\mathrm{V}_{\mathrm{i}} \mathrm{V}_{\mathrm{i}}$ ("puxa-puxa', “doce”), (b) a sufixação intensiva ("chororô', "choro excessivo") e (c) a prefixação reduplicativa em nomes de parentesco ('vovó'), hipocorísticos ('Dedé', a partir do antropônimo 'André') e na interação pelo baby-talk ('neneca', redução afetiva de 'boneca').

O texto se estrutura da seguinte maneira: na próxima seção, definimos reduplicação, apresentando um pequeno conjunto de exemplos do português brasileiro. Na sequência, mos- 
tramos que muitas onomatopeias apresentam formas replicadas, mas não devem ser entendidas como oriundas de um processo morfológico de reduplicação. Logo após, com base em Garcia (1996), distinguimos reduplicação de repetição. Por fim, analisamos cada padrão de reduplicação existente em português, sobretudo na variante brasileira.

\section{REDUPLICAÇÃO: PRIMEIRAS IDEIAS}

A reduplicação é um processo morfológico que envolve a cópia de material fonológico de uma base, à qual se chega, algumas vezes, por meio de um encurtamento, como em 'André' > 'Dé' > 'Dedé'. Pode ocasionar a repetição de toda a palavra ou de apenas parte dela, à esquerda ('pai' > 'papai') ou à direita ('bolo' > 'bololô'), com alteração fonológica ('madrinha' > 'dindinha') ou não ('Raquel' > 'Quequel'). Dito de outra maneira, a reduplicação pode ser total, como nos dados em (01) e (02), ou parcial, como em (03). A diferença entre (01) e (02) reside no fato de, em (02), haver um mecanismo de redução antes da cópia; em (03), um ou mais segmentos tornam as sequências fonicamente diferentes, embora, como em (02), também haja encurtamento:

(01) come-come (jogo eletrônico); pega-pega (brincadeira infantil)

(02) bumbum (bunda); vovó (avó); Lili (Sueli)

(03) Bebel (Isabel); bololô (embolação); dodói (machucado)

Nas línguas do mundo, a reduplicação é usada em flexões, para transmitir uma função gramatical, tal como a pluralidade, e em derivações lexicais para criar novas palavras com valores semânticos os mais variados. Casos conhecidos de redobro flexional são a prefixação reduplicativa em Agta e a sufixação reduplicativa em Saho, como nos dados exemplificados, a seguir, extraídos de Marantz (1982). Em ambos os casos, a reduplicação manifesta o número plural:

(04) Agta

(a) takki 'perna' > taktakki 'pernas'

(b) uffu 'coxa' > ufuffu 'coxas'

Saho

(a) lafa 'osso' > lafof 'ossos'

(b) illa 'primavera' > illol 'primaveras'

Línguas indo-européias formalmente utilizavam a reduplicação para criar uma série de formas verbais, especialmente no pretérito perfeito. Nas línguas indo-européias mais conhecidas, mas já extintas, muitas dessas formas verbais são encontradas (KIYOMI, 1995): 
(05) Latim: spondeo, spopondi (“eu juro, eu jurei”)

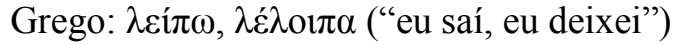

Gótico: háitan, haíháit ("nomear, eu nomeei”)

No tok pisin, crioulo inglês da Papua Nova Guiné (Oceania), observa-se o redobro total na formação de verbos, como tok-tok ("falar") e luk-luk (“olhar"). Nos crioulos franceses (COUTO, 1999), o emprego do fenômeno também é frequente, como em tous-touse ("tossir sem parar"), bouz-bouze ("mexer-se ligeiramente"). Logo, é notório que a reduplicação é um processo presente em quase todas as línguas do mundo. Isso leva Couto a defender a tese de que a reduplicação pode ser um dos primeiros processos morfológicos e gramaticais a existir, já que parte da simples junção de duas formas da maneira mais econômica: através de uma cópia.

Reduplicação é o termo padrão para esse fenômeno na literatura linguística. Outros são usados ocasionalmente: clonagem, duplicação e repetição (CRYSTAL, 1997). Como lembra Couto (2000), a reduplicação não é um fenômeno desconhecido das gramáticas tradicionais; no entanto, é tratada, nesse tipo de compêndio, sobretudo como composição. É exemplificado, quase sempre, como formas como 'luze-luze', 'ruge-ruge' e 'quero-quero', nem todas com o mesmo estatuto na língua, tal como apontado por Vialli (2011). O fenômeno da reduplicação encontra-se na lista dos processos marginais de formação de palavras do português não apenas por apresentar escassez de análises linguísticas e dificuldades em sua delimitação, mas também porque sua regularidade está na relação da morfologia com a fonologia (GONÇALVES, 2004).

\section{REPETIÇÃO E REDUPLICAÇÃO}

Couto (1999) observa que o fenômeno da reduplicação também aparece nos tratados de retórica, como em Tavares (1978), que apresenta a epizeuxe (ou reduplicação) entre as figuras feitas por "repetição ou excesso". Exemplifica a repetição seguida pelo mesmo vocábulo com um trecho de Gonçalves Dias: "São uns olhos verdes, verdes...". Com o objetivo de deixar clara a diferença entre repetição e reduplicação, podemos recorrer a Garcia (1996):

repetição é a reaparição de um ou mais elementos linguísticos depois de sua primeira ocorrência no texto. Como processo expressivo, não só intratextual, mas também intertextual, a repetição [...] constitui um dos recursos mais efetivos para a intensificação da linguagem nos níveis fonológico, morfológico e sintático. 
Como se depreende da citação, a repetição pode ser frasal ou lexical; no entanto, somente a lexical implica a aparição de palavras autônomas, como substantivos, verbos, adjetivos e advérbios. Ora, nesse sentido, a chamada epizeuxe é um caso de repetição discursiva, muito diferente de exemplos como "Eles ficam nesse canta-canta e não fazem nada", em que temos como resultado da repetição um substantivo. Nesse exemplo, não há mera repetição, mas um processo morfológico de reduplicação em que a clonagem da forma verbal leva à formação de uma nova palavra.

Outros exemplos de repetição vocabular utilizada com função expressiva - e que, portanto, não devem ser confundidos com a reduplicação - são os seguintes, extraídos da Internet, letras de músicas ou obras literárias (VIALLI, 2013):

(06) O sol chegou, tão atrevido.

Penetrando na cortina.

Eu posso ver todo seu corpo.

Descoberto, linda, linda (Zezé di Camargo e Luciano).

Me Abraça e Me Beija, Amor

Que o meu Coração chamou, chamou (Banda Calipso).

Ela é uma mulher grossa, grossa, grossa.

E eu dizia:

- Ainda é cedo, cedo, cedo, cedo, cedo.

(Legião Urbana).

Te amo muito, muito, muito!

Wierzbicka (1986) observa que repetição e reduplicação são fenômenos bem diferenciados funcionalmente. O primeiro é marcado por pausa, representada por meio de uma vírgula na escrita ('Ele caminha devagar, devagar'); o último não admite pausa ou vírgula na escrita e constitui novo item lexical ('bate-bate' — "brinquedo de parque de diversões"). A autora observa que, nos casos de reduplicação, como processo, apesar de haver relação de significado com a base original, o produto é um item diferente, que mantém relação morfofonológica com a palavra-fonte; na repetição vocabular, a ideia veiculada é sempre a de intensificação. 


\section{REDEFININDO A REDUPLICAÇÃO}

Retomando Couto (1999), pode-se concluir que na repetição existe total igualdade entre a base e a cópia do ponto de vista formal e funcional; na reduplicação, essa igualdade se dá apenas formalmente, podendo a cópia da base ser total ou parcial. $\mathrm{O}$ autor decide, então, adotar o conceito de reduplicação formulado por Kiyomi (1995), transcrito em (07), a seguir:

(07) Reduplicação:

Dada uma palavra com a forma fonológica X, a reduplicação refere-se a XX ou xX (em que $\mathrm{x}$ é a parte de $\mathrm{X}$ e $\mathrm{x}$ pode aparecer antes, após ou no interior de $\mathrm{X}$ ).

Condições:

(i) $\mathrm{XX}$ ou $\mathrm{xX}$ devem ser relacionados semanticamente a $\mathrm{X}$.

(ii) $\mathrm{XX}$ ou $\mathrm{XX}$ devem ser produtivos.

Dessa forma, a reduplicação pode ser total $(\mathrm{XX})$ ou parcial $(\mathrm{xX})$ e a forma reduplicada não preserva a mesma função semântica e gramatical da base. Quando a reduplicação for parcial, os segmentos copiados podem pertencer ao início, meio ou final da base original; por isso mesmo, a reduplicação é um tipo especial de afixação (GONÇALVES, 2009), um processo morfológico que, de acordo com Key (1965), pode dar ideia de iteração, pluralidade, intensificação, distributividade, diminuição e mudança de categoria gramatical.

Ao analisar o alcance da reduplicação em português, Albuquerque \& Gonçalves (2004: 47), como Kyiomi (1995) estabelecem condições para que se identifiquem formas resultantes desse processo:

(i) a base copiada deve ser sincronicamente depreendida e haver relação de significado entre base e produto. Nesse caso, 'bebelo' é uma reduplicação porque a base 'cabelo' é reconhecida sincronicamente. O mesmo não acontece, por exemplo, com 'mamão', em que a isolabilidade do suposto prefixo reduplicativo destruiria as relações de significado no interior da palavra, uma vez que a noção de 'mão' não está contida em 'mamão';

(ii) o resultado do processo deve ser uma forma com função lexical ou expressiva de avaliação (BASILIO, 1987), como ocorre, respectivamente, em 'corre-corre', que denomina um evento, e em 'Dedé', hipocorístico do antropônimo 'André', marcado pela expressão de afeto;

(iii) a forma resultante não deve possuir valor onomatopaico, o que caracterizaria simplesmente a reprodução de um som e não uma cópia feita a partir de uma base, como 'fonfom' e 'auau'. Essas formações são casos de reduplicação bem motivados onomatopaicamente, ao contrário de 'bate-bate' e 'pega-pega', entre outros. 


\section{REDUPLICAÇÃO E ONOMATOPEIA}

Couto (1999, 2000), Albuquerque \& Gonçalves (2004) e Vialli (2008) alertam para as comparações entre onomatopeia e reduplicação, também feitas por diversos autores já citados. Key (1965) aponta que, por ter como função primordial a imitação de sons, a onomatopeia não pode expressar funções gramaticais, tal qual a reduplicação. Alguns exemplos de onomatopeia que se assemelham à reduplicação são elencados em (08), a seguir. Sem dúvida alguma, os dados em (08) exibem sequências replicadas e formalmente fazem uso da repetição, mas de modo algum resultam de um processo produtivo, como prevê a condição (07ii) acima. Nesses casos, a forma resultante é motivada pela reprodução aproximada, imitativa, com os recursos fonológicos de que a língua dispõe, de algum som/ruído natural:

(08) auau = cachorro latindo

bibi = buzina acionada; pedido de passagem; carro (infantil)

fonfom = buzina tocando; pedido de passagem

gluglu = gorgoletar do peru; praticar sexo (fazer gluglu)

quero-quero $=$ nome de uma ave que pretensamente faz esse som

tique-taque $=$ barulho do relógio

chuá-chuá = água caindo abundantemente

trim-trim $=$ telefone tocando

plimplim $=$ Rede Globo (som emitido durante intervalos comerciais)

toc-toc $=$ batida na porta

Como se vê em (08), ruídos, gritos, canto de animais, sons da natureza, barulho de máquinas, timbre da voz humana, entre outros domínios, fazem parte do universo das onomatopeias. No domínio da fala, há várias onomatopeias com três sílabas idênticas (09), a primeira delas criada muito recentemente:

(09) mimimi $=$ utilizado para satirizar alguém que passa a vida reclamando nhenhenhém = lamúria; resmungo tititi $=$ vozerio; confusão de vozes zunzunzum $=$ excessiva confusão

Algumas onomatopeias acabam adquirindo significados especializados, através da metáfora ou da metonímia. É o que se observa com 'piu-piu', barulho emitido pelo pinto, que, por também fazer referência ao órgão genital masculino, acaba sendo usada eufemisticamente como sinônimo de "pênis", sobretudo de crianças.

Muitas formas replicadas fazem referência ao domínio do sexo e envolvem redobro total, ainda que não seja possível identificar uma base, o que torna questionável o estatuto de 
reduplicação. É provável que algumas tenham motivação onomatopaica, por conta do ruído durante a prática sexual:

(10) nheco-nheco; fuc-fuc-; lepo-lepo; vuc-vuc; tuf-tuf; lesco-lesco

Algumas onomatopeias vêm prontas de outras línguas, como o inglês (11). Além disso, muitas formas do inglês acabam sendo reinterpretadas por falantes do português como casos de reduplicação, por conta da semelhança sonora que apresentam com palavras já consagradas na língua (12), ainda que possam ter vindo do inglês:

(11) bang-bang = barulho de tiros; tiroteio; gênero de filme sniff-sniff = som de alguém chorando; chororô

(12) what's up >> zap-zap "aplicativo de celular" self-service $>>$ serve-serve "restaurante em que se o cliente se serve"

Por conta da influência das línguas africanas na formação histórica do português, muitas delas com amplo uso da reduplicação, várias palavras com sílabas idênticas acabaram chegando até nós, muito embora não sejam casos de reduplicação, aqui entendida como em (07), ou seja, tal como concebida por Kiyomi (1995):

(13) gogó, Iaiá, tutu, cocô, babá, nenê(m), bobó, chuchu, fofoca, babaca

Também é de origem africana a expressão 'lero-lero', que significa “conversa fiada; palavreado vazio". Essa forma, nos dias de hoje, é sentida como reduplicada porque sofreu o processo de truncamento e 'lero', sozinha', assumiu o significado de conversa, sem conotação negativa, como se observa no exemplo a seguir. Com isso, 'lero-lero' passa a ser entendida como um caso de reduplicação em português:

(14)@guiafolha Muito obrigada pela atenção, em nome de toda a equipe do Guia! E bom show aqui em SP. Bom gente, foi um prazer imenso levar esse lero com vocês. Espero que vcs tb tenham gostado. Beijão!!! (Folha de São Paulo, 27/04/2011).

\section{SUFIXAÇÃO REDUPLICATIVA}

De acordo com Couto (1999), Araújo (2000) e Albuquerque \& Gonçalves (2004), a reduplicação é um processo altamente produtivo no português brasileiro (PB), sendo, mostram Villalva \& Gonçalves (no prelo), de produtividade muito limitada no português europeu e em 
outras variantes do mundo lusófono. Na variedade brasileira, novas formas reduplicadas são facilmente encontradas. Por exemplo, o acréscimo do molde subespecificado VCV (vogalconsoante-vogal) no final da palavra expressa intensificação:

\begin{tabular}{|c|c|c|c|}
\hline (15) & chor + o & chororô & "choro excessivo" \\
\hline & bol+o & bololô & "grande aglomeração" \\
\hline & trel $+\mathrm{a}$ & trelelê & "dar confiança demais" \\
\hline & $\mathrm{baf}+\mathrm{o}$ & bafafá & "confusão; gritaria" \\
\hline
\end{tabular}

Em todas as palavras que expressam intensidade usando esta estratégia, as vogais resultantes são sempre idênticas, existindo, portanto, perfeita harmonia na melodia vocálica. Exemplos como os de (15) nos levam a considerar que o processo de cópia faz uso dos segmentos da raiz (não da palavra),uma vez que o índice temático da base nunca aparece. Assim, a partir de 'ch[o]ro', temos 'chororô', instanciando uma vogal média-fechada, [o], como o núcleo das três sílabas da palavra resultante. O mesmo pode ser dito sobre 'b[a]fo', em que a eliminação da vogal temática produz três vogais baixas idênticas ('bafafá').

Esse padrão de reduplicação aparece em outros casos, sempre expressando intensidade, como 'piriri’ (“diarreia excessiva”) e 'sururu' (“confusão”), nos quais é difícil identificar uma base, sendo impossível uma interpretação mais composicional. Para as palavras reduplicativas desse grupo, podemos definir um modelo fonológico abstrato, $C(C) V_{i} C_{j} V_{i} C_{j} V_{i}$, em que $i$ e $j$, subscritos, indicam identidade completa de segmentos e C e V, consoante e vogal, nesta ordem. Parênteses representam opcionalidade: a segunda consoante pode ou não existir: cf. 'bafafá' vs. 'trelelê'.

\section{COMPOSIÇÃ̃O $V_{I} V_{I}$}

Um segundo caso de reduplicação, igualmente mais comum no português brasileiro que em outras variedades, envolve a duplicação de um verbo para formar um composto $V_{i} V_{i}$, em que $\mathrm{V}$ representa verbo $\mathrm{e}_{\mathrm{i}}$, subscrito, identidade entre as formas. Os produtos podem transmitir dois significados: ação (16a) ou objeto (16b). Em alguns casos, ambos os sentidos podem ser observados na mesma palavra (16c):

(16) a. borra-borra

b. bate-bate

c. pula-pula "ato de borrar repetidamente"

"brinquedo do parque de diversões"

"ato de pular repetidamente/brinquedo" 
As bases de compostos $\mathrm{V}_{\mathrm{i}} \mathrm{V}_{\mathrm{i}}$ são geralmente disslábicas ('chupa-chupa', “tipo de picolé"; 'treme-treme', "nome de um edifício em São Paulo"; 'pisca-pisca', "luminoso que pisca repetidamente") ${ }^{1}$. Há também casos como 'empurra-empurra", 'espreme-espreme' e 'esbarra-esbarra', com três sílabas, mas a primeira é sempre desprovida de onset (ataque silábico, elemento pré-nuclear). Uma vez que a reduplicação de bases verbais é regida por exigências prosódicas, os produtos sempre terminam em sílabas abertas (sem coda, elemento de travamento). Finalmente, a principal característica do processo é a seleção da terceira pessoa do singular do presente do indicativo (P3 Ind Pres): assumimos que essa é a forma não-marcada do paradigma do verbo, fato que permite a releitura do verbo como substantivo.

Evidência de que P3 Ind Pres é, de fato, a forma não-marcada em português é o fato de figurar em compostos VS, como em (17), composição com estrutura muito semelhante à de sintagmas verbais, e em compostos $\mathrm{V}_{\mathrm{i}} \mathrm{V}_{\mathrm{j}}$, com dois verbos diferentes igualmente na terceira pessoa do singular do presente do indicativo:

(17)

$\begin{array}{ll}\text { guarda-costas } & \text { "tipo de segurança" } \\ \text { lava-louça(s) } & \text { "instrumento para lavar louças" } \\ \text { quebra-cabeça(s) } & \text { "jogo de montagem" } \\ \text { porta-copos } & \text { "objeto para pendurar copos" } \\ \text { paraquedas } & \text { "artefato de lona para amortecer a queda" }\end{array}$

(18) bate-entope "iguaria que logo sacia"

sobe-e-desce "subir e descer repetidas vezes"

leva-e-traz "fofoqueiro"

morde-e-assopra "indivíduo que critica alguém e logo depois elogia"

Vale a pena comentar o tratamento dado à reduplicação verbal no italiano por Thornton (2008), pois também vale para o português. A autora destaca exemplos como fuggi-fuggi (“debandada") e copia-copia (“cópia generalizada"), afirmando a composição $\mathrm{V}_{\mathrm{i}} \mathrm{V}_{\mathrm{i}}$ é responsável pela nominalização de ações em italiano, sendo muito usual nessa língua. Ela mostra que, no espanhol, esse tipo de composto é responsável pela nomeação de plantas (duermeduerme, "dormideira"), brincadeiras (pega-pega, "brincadeira de correr"), jogos (mata-mata, "bola de gude") e pessoas (chapa-chapa, "rico"). Guilbert (1971) elenca poucos nomes oriundos dessa operação morfológica em francês; são eles: (a) instrumentos: coupe-coupe ("facão") e vire-vire ("ventilador") e (b) jogos: passe-passe ("abracadabra") e cache-cache ("esconde-

1 Todas essas formas apresentam interpretação mais verbal, uma vez que também atualizam um significado mais aspectual (iterativo), remetendo a algo feito excessivamente. 
esconde"). Desse modo, o processo parece bem mais usual em italiano que em outras línguas neolatinas.

Os compostos $\mathrm{V}_{\mathrm{i}} \mathrm{V}_{\mathrm{i}}$ em italiano, como compra-compra ("ato de comprar repetidamente") e parla-parla ("ato de falar muito e dizer pouco"), são nomes de ação bem mais padronizados que em espanhol e francês, o que leva Thornton (2008) a afirmar que é o italiano a língua em que o uso da reduplicação de base verbal se faz mais presente. De modo algum concordamos com a autora, pois a variedade brasileira faz amplo uso desse mecanismo que, na maioria esmagadora dos casos, apresenta conteúdo iterativo: ato de praticar a ação expressa pela base reiteradas vezes.

Couto $(1999,2000)$ classifica as diversas formas de reduplicação $V_{i} V_{i}$, por ele observadas, da seguinte maneira:

(a) Formas citadas pelas gramáticas, algumas das quais em desuso:

(19) (i) bule-bule: '?'

(ii) corre-corre: 'correria',

(iii) luze-luze: 'pirilampo',

(iv) pega-pega: '1.carrapicho; 2. conflito; 3. prisão em massa; 4. brinquedo',

(v) ruge-ruge: '1. ruído por saias que roçam o chão; 2 . rugido ; 3 . barulho'

(b) Formas usadas como nomes próprios:

(20) (i) troca-troca: 'nome de feira popular de Olhos d'água, Goiás',

(ii) Vaivai: 'nome da escola de samba mais famosa de São Paulo'

(c) Formas não encontradas nas gramáticas, mas já dicionarizadas:

(21) (i) bate-bate: '1. movimento constante de objetos que se chocam; 2. batida',

(ii) lambe-lambe: '1. fotógrafo; 2 . primeira fila dos teatros de revistas',

(iii) lufa-lufa: 'grande afã, azáfama',

(iv) mexe-mexe: 'tipo de jogo',

(v) pisca-pisca: '1. cacoete de piscar; 2. ato de piscar seguidamente, 3. farol intermitente, 4. farolete dos automóveis',

(vi) pula-pula: ' 1 . tipo de ave, 2. ato de pular repetidamente, 3. brinquedo'

(vii) puxa-puxa: '1. doce ou bala de consistência elástica e grudenta; 2. espécie de alféloa, puxa',

(viii) quebra-quebra: '1. arruaça com depredações; 2. cobra-de-vidro',

(ix) roque-roque: ' 1 . Ato de roer; 2 . tipo de peixe'.

(d) Formas que não constam nas gramáticas nem estão dicionarizadas: 
(22) (i) beija-beija: 'ação de várias pessoas beijando umas às outras',

(ii) empurra-empurra: 'tumulto, em que cada um quer se safar primeiro',

(iii) gira-gira: 'brinquedo giratório de parquinho infantil',

(iv) mata-mata: 'jogo decisivo’

Os mais de cinquenta dados recolhidos por Vialli (2013) — e diferentes dos já citados por Couto (1999, 2000), Araújo (2000), Albuquerque \& Gonçalves (2004) e Vialli (2008) — evidenciam que, pelo menos na variedade brasileira (PB), a reduplicação de bases verbais é tão ou mais usual que em italiano, o que nos leva a repensar a afirmação feita por Thornton (2008).

No PB, há um padrão associado a esse tipo de reduplicação. No polo formal, o tema de um verbo de ação dissilábico ('pega-pega', 'pula-pula', 'corre-corre') ou trissilábico sem onset ('agarra-agarra', espreme-espreme', 'empurra-empurra') é repetido e o redobro cria um substantivo. No polo semântico, dois significados geralmente emergem. O mais básico (e comum a todas as formações) é o de evento, como em 'pisca-pisca' significando simplesmente "piscar repetidas vezes". Nessa palavra, ocorre interpretação metafórica da ação expressa pelo verbo, isto é, como o evento se desdobra no tempo, manifesta o aspecto iterativo. Nas demais acepções, ocorre nova extensão semântica e o significado se torna mais fixo, como coisa ("pisca-pisca' como "luzes de Natal" ou "alerta do automóvel”). Nesse caso, o nome é acessado estaticamente e a interpretação que leva ao nome-coisa é feita por meio da metonímia, uma vez que o objeto tem a propriedade de piscar reiteradas vezes. No quadro abaixo, distribuímos alguns dos dados de Vialli (2013) com base no tipo de significado que manifestam, fornecendo um exemplo para cada uso.

Tabela 1 - Exemplos contextualizados de reduplicação de base verbal.

\begin{tabular}{|c|c|c|}
\hline Forma & Sentido & Exemplo \\
\hline Acende-acende & evento & $\begin{array}{l}\text { O fósforo não acendia de jeito nenhum. O vento sempre apagava e } \\
\text { a gente ficou naquele acende-acende rindo pra caramba! }\end{array}$ \\
\hline Agarra-agarra & Evento & Eu já não aguento mais ficar nesse agarra-agarra no portão. \\
\hline Alisa-alisa & Evento & $\begin{array}{l}\text { E não diga que gosta de cafuné não... que você não vai ter sosse- } \\
\text { go!! Vai ser um alisa-alisa danado!! }\end{array}$ \\
\hline Arranha-arranha & Evento & $\begin{array}{l}\text { Disseram que foi um empurra-empurra, um arranha-arranha que só } \\
\text { Deus e ainda naquele calor, aff... }\end{array}$ \\
\hline Ataca-ataca & Evento & E de repente, foi aquele ataca-ataca na mesa de doces. Um horror! \\
\hline Bate-bate & Evento & $\begin{array}{l}\text { "Arriscavam um tímido mexer da cabeça, acompanhando o bate- } \\
\text { bate do compasso". }\end{array}$ \\
\hline
\end{tabular}


Pontos de Interrogação, v. 5, n. 1, jan./jul. 2015

Revista do Programa de Pós-Graduação em Crítica Cultural

\begin{tabular}{|c|c|c|}
\hline & Coisa & $\begin{array}{l}\text { "Carrinho de bate-bate do parque de diversões solta e acidenta } \\
\text { menino de } 7 \text { anos". }\end{array}$ \\
\hline Beija-beija & Evento & Agora vai terminar a dança do beija-beija \\
\hline Bole-bole & Evento & Dança do bole-bole (música) \\
\hline \multirow[t]{2}{*}{ Cai-cai } & Evento & $\begin{array}{l}\text { A unção do cai-cai iniciou-se com o americano Randy Clark, que } \\
\text { foi ordenado pastor em } 1950 \text {. }\end{array}$ \\
\hline & Coisa & $\begin{array}{l}\text { Fama de "cai-cai" vira brincadeira com Neymar no Twitter; veja } \\
\text { frases mais engraçadas. }\end{array}$ \\
\hline Canta-canta & Evento & "Eles ficam nesse canta-canta e não fazem nada." \\
\hline Cheira-cheira & Evento & Depois as posições se invertem e começa um cheira-cheira danado. \\
\hline \multirow[t]{2}{*}{ Cisca-cisca } & Evento & $\begin{array}{l}\text { Lembro que lá em casa era agitado sempre... um cisca-cisca dana- } \\
\text { do quase o dia todo... }\end{array}$ \\
\hline & Coisa & $\begin{array}{l}\text { Como dizem os meus amigos gaúchos, vocês contrataram um } \\
\text { eterno reserva, um cisca-cisca. }\end{array}$ \\
\hline Coça-coça & Evento & $\begin{array}{l}\text { Coça-coça. Seu cão ou gatinho se coça demais em partes do corpo } \\
\text { como patas, orelhas e olhos? }\end{array}$ \\
\hline \multirow[t]{2}{*}{ Come-come } & Evento & $\begin{array}{l}\text { E acabou a novela sem ninguém tê-la "comido", justo numa novela } \\
\text { que, desde o início, foi um "come-come" adoidado. }\end{array}$ \\
\hline & Coisa & $\begin{array}{l}\text { Todos conhecem o famoso Pacman, vulgo come-come. É só comer as } \\
\text { bolinhas e escapar dos inimigos. }\end{array}$ \\
\hline Empurra-empurra & Evento & $\begin{array}{l}\text { Confusão e empurra-empurra no final dos treinos abertos do UFC } \\
\text { em São Paulo. }\end{array}$ \\
\hline \multirow[t]{2}{*}{ Engana-engana } & Evento & $\begin{array}{l}\text { A educação nunca foi prioridade em nenhum governo sempre é um } \\
\text { engana-engana: governo fazendo de conta que paga um bom salá- } \\
\text { rio ao professor e o professor faz de conta que ensina. }\end{array}$ \\
\hline & Coisa & $\begin{array}{l}\text { Chamo de engana-engana aquele tipo onde uma pessoa finge ser } \\
\text { competente para a organização (e o pior, o chefe acredita). }\end{array}$ \\
\hline \multirow[t]{2}{*}{ Esconde-esconde } & Evento & $\begin{array}{l}\text { De toda a prova apenas um não escondeu o jogo. Foi o canadense } \\
\text { Pascal Wollach que ficou com o } 2^{\circ} \text { tempo da prova com 55:69 e } \\
\text { fez sua melhor marca pessoal. O resto foi um esconde-esconde } \\
\text { geral. }\end{array}$ \\
\hline & Coisa & $\begin{array}{l}\text { Veja como inovar no jogo do Esconde-Esconde, que pode ser } \\
\text { jogado por crianças a partir dos } 2 \text { anos de idade. }\end{array}$ \\
\hline \multirow[t]{2}{*}{ Lambe-lambe } & Evento & $\begin{array}{l}\text { A superlotação felina em casa prejudicou o dengo do Nico. Esta } \\
\text { semana tá um lambe-lambe do cacete! }\end{array}$ \\
\hline & Coisa & $\begin{array}{l}\text { O lambe-lambe basicamente é um pôster de papel colado com cola, } \\
\text { em muros e postes. }\end{array}$ \\
\hline \multirow[t]{2}{*}{ Mata-mata } & Evento & "Mata-mata entre gangues". \\
\hline & Coisa & $\begin{array}{l}\text { "O mata-mata decisivo, com jogos de ida e volta, começa com } 32 \\
\text { equipes." }\end{array}$ \\
\hline \multirow[t]{2}{*}{ Mexe-mexe } & Evento & "É um mexe-mexe, é um desaponta" (música) \\
\hline & Coisa & $\begin{array}{l}\text { O jogo proposto pelo fabricante é o nosso "Mexe-mexe" (regras } \\
\text { abaixo). }\end{array}$ \\
\hline
\end{tabular}




\begin{tabular}{|l|l|l|}
\hline Mija-mija & Evento & $\begin{array}{l}\text { "Eu já estava na fase mija-mija e tinha que ir ao banheiro a toda } \\
\text { hora". }\end{array}$ \\
\hline Pega-pega & Coisa & $\begin{array}{l}\text { "Porque será que os mija-mija (lava-vidros dos carros) ficam sem água } \\
\text { quando fazem mais falta?" }\end{array}$ \\
\hline & Evento & Mas às vezes, sinto eu, porém, o que se vê é um pega-pega danado! \\
\cline { 2 - 3 } & Evento & $\begin{array}{l}\text { O pega-pega ou apanhada é uma brincadeira infantil muito conhe- } \\
\text { cida. }\end{array}$ \\
\hline Rala-rala & Evento & Ninguém resolve o problema do pinga-pinga do ar-condicionado. \\
\hline Toca-toca & Evento & $\begin{array}{l}\text { No samba ela gosta do rala-rala. Me trocou pela garrafa. Não a- } \\
\text { guentou e foi ralar. }\end{array}$ \\
\cline { 2 - 4 } & Coisa & $\begin{array}{l}\text { Forró do toca-toca E a galera nesse tal de toca- toca quero ver você } \\
\text { dançando nesse refrão. }\end{array}$ \\
\hline Troca-troca & Evento & $\begin{array}{l}\text { Peça sua música aqui no Toca-Toca e dedique a quem você quiser. } \\
\text { Troca-troca virtual: livre-se do que não presta e adquira novos } \\
\text { objetos. }\end{array}$ \\
\hline & Coisa & $\begin{array}{l}\text { Evitar o troca-troca não é garantia de que o menino será heterosse- } \\
\text { xual quando for adulto. }\end{array}$ \\
\hline
\end{tabular}

Como se vê, a maioria só veicula a noção de evento, tendo, portanto, leitura mais verbal. Mesmo aqueles cuja referência primeira parece apontar para a noção de coisa, como 'batebate' e 'pega-pega', também podem ser usados com valor de evento, o que justifica argumentar que, no PB, a composição $\mathrm{V}_{\mathrm{i}} \mathrm{V}_{\mathrm{i}}$, assim como no italiano (THORNTON, 2008), constitui padrão regular e produtivo de formação de palavras. As interpretações mais idiossincráticas — se é que podemos nos referir a elas dessa maneira - decorrem de um processo de lexicalização fortemente motivado pela metonímia. Assumimos, aqui, seguindo Brinton \& Traugott (2005), que a lexicalização é o processo através do qual duas ou mais unidades linguísticas se transformam em uma unidade autônoma. Nesse caso, então, o termo se refere à perda da composicionalidade morfológica e semântica, tendo em que vista que a unidade deixa de ser interpretada por acesso às partes e passa a ser tomada holisticamente.

\section{PREFIXAÇÃO REDUPLICATIVA}

Além dos casos já comentados de reduplicação (padrão sufixal, como em 'chororô', e composição $\mathrm{V}_{\mathrm{i}} \mathrm{V}_{\mathrm{i}}$, como em 'puxa-puxa'), o português apresenta outros casos, alguns de uso 
mais geral, como nas situações de baby-talk e na formação de hipocorísticos, e outro mais específico: a prefixação afetiva em nomes de parentesco. Comecemos com esse último caso.

Há, no léxico do português, um grupo de formas reduplicadas constituído por apenas seis palavras: o de nomes afetivos de parentela. $\mathrm{O}$ reduzido número de dados, no entanto, não causa estranhamento, já que as relações de parentesco são limitadas e partem de chamada "família nuclear", o casal, para outros membros mais distantes, ligados por laços de consanguinidade (VILELA, 1979). Assim, uma estrutura familiar mais ampla inclui, além dos pais, (i) os irmãos, (ii) os filhos dos irmãos, (iii) os pais dos pais, (iv) os irmãos dos pais, e (v) os filhos dos irmãos dos pais (AUGÉ, 1975). Em português, são passíveis de reduplicação apenas os termos que denominam os pais ('papai', 'mamãe'), os pais dos pais ('vovô', 'vovó') e os irmãos dos pais ('titio', 'titia'). Esse grupo de palavras é analisado em Gonçalves (2010).

Em todos os dados, o reduplicante é um prefixo e tem o formato CV (Consoante+Vogal). Em primeiro lugar, a estrutura vazia $\mathrm{CV}$ é adjungida à esquerda da base e desencadeia um processo automático de cópia pela esquerda. Tomemos como exemplo a forma 'pai', que ilustra o comportamento de todas as demais, à exceção de 'vovô' e 'vovó'. No caso de 'pai', a oclusiva /p/ é associada à posição de $\mathrm{C}$ e, logo após, a vogal /a/ se liga à posição de $\mathrm{V}$ do molde $\mathrm{CV}$ adjungido à esquerda da base. O material que sobra - a semivogal $/ \mathrm{j} /$ - é descartado, o que leva à formação de 'papai'. No caso de 'vovô' e 'vovó', a cópia para o molde prefixal CV parte das formas encurtadas 'vó' e 'vô', bem mais afetivas que as plenas correspondentes. Desse modo, a reduplicação passa a ser total, uma vez que a base e o reduplicante são idênticos.

Em sua análise sobre a reduplicação, Couto (1999) aborda o fenômeno do baby-talk. Segundo ele, baby-talk é a linguagem utilizada pelos adultos ao se comunicarem com crianças, na tentativa de reproduzir a fala infantil, numa espécie de adaptação. Segundo Crystal (1997: 38), o fenômeno é também conhecido como motherese ("linguagem materna"): adultos, ao falar com crianças pequenas, ou mesmo mães, situação na qual é mais comum o babytalk, fazem uso de um tipo de linguagem altamente distintiva e, mostra Vialli (2008), a reduplicação constitui um dos recursos encontrados nesse tipo de interação "frequentemente estereotipado de pronúncia e palavras" (CRYSTAL, 1997: 38).

Nesse tipo de linguagem, podemos perceber padrões prosodicamente bem organizados, de modo que uma abordagem morfofonológica é a mais apropriada para dar conta desse pro- 
cesso. Vejam-se os dados em (23), a seguir, extraídos de Vialli (2008), nos quais os diacríticos $\left(^{\wedge}\right)$ e $(')$ representam vogais médias fechadas e abertas, respectivamente, o ponto marca fronteira silábica e o símbolo ('), antes de uma sílaba, o acento lexical:

\begin{tabular}{|c|c|c|c|c|}
\hline $\begin{array}{l}\text { chupeta } \\
\text { martelo } \\
\text { iogurte } \\
\text { biscoito }\end{array}$ & $\begin{array}{l}\text { [pê.'pê.ta] } \\
\text { [te.'té.lu] } \\
\text { [gu.'gu.tsi] } \\
\text { [kô.'kô.tu] }\end{array}$ & $\begin{array}{l}\text { boneca } \\
\text { mamadeira } \\
\text { estrela } \\
\text { pirulito }\end{array}$ & $\begin{array}{l}\text { [né.'né.ka] } \\
\text { [dê.'dê.ra] } \\
\text { [tê.'tê.la] } \\
\text { [li.'li.tu] }\end{array}$ & $\begin{array}{l}\text { cabelo [be.'bêlu] } \\
\text { chapéu [pé.'péw] } \\
\text { picolé [lé.'llé] } \\
\text { dormiu [mi.'miw] }\end{array}$ \\
\hline
\end{tabular}

Observando os dados, podemos prever etapas para a formação das formas em (23), carinhosamente emitidas para crianças ou produzidas por elas: (1) o encurtamento da palavra de base; (2) a atuação de restrições de silábicas sobre o material fonológico encurtado; e (3) a anexação do reduplicante $\mathrm{CV}$ à esquerda. Nesse caso, portanto, a reduplicação é também do tipo prefixal. Pelos dados, percebemos que é preservada, da esquerda para a direita, toda a sequência fonológica a partir da sílaba tônica. Em (24), representa-se o processo de encurtamento. O símbolo $(*)$, acima da sílaba, representa a tônica e o tachado, o material que não será aproveitado:

Sobra ehupeta [....] ['pê.ta]

$(*)$ ehapéu [...] ["péw]
(*) estrela [.....] ['trê.la]
(*)

mamadeira

[......]

['dej.ra]
(*)

picolé

[..]

['lé]

O material fonológico que sobra é bastante diversificado, do ponto de vista da estruturação silábica, apresentando os seguintes formatos: CV.CV ('peta' $<<$ 'chupeta'), CVC ('péu' $<<$ 'chapéu'), CVC.CV ('coito' << 'biscoito'), CCV.CV ('trela' << 'estrela'), CV ('lê' << 'picolé'). Como, nas primeiras fases de aquisição da linguagem, sílabas complexas tendem a ser simplificadas (SMOLENSKY, 1996), no baby-talk, que constitui tentativa mimética de reproduzir a fala de crianças pequenas, são extremamente relevantes as condições de boa-formação silábica. Essas condições atuam no material fonológico encurtado, exigindo tanto a presença do ataque (onset da sílaba, consoante em posição explosiva) quanto o bloqueio de complexidade nesse constituinte, ou seja, deve haver um ataque, mas não um grupo consonantal. Assim, as formas ['pê.ta] ('chupeta'), ['té.lu] ('martelo'), ['pa.tu] ('sapato'), ['lé] ('picolé) e ['bê.lu] ('cabelo'), entre outras, por já serem bem-formadas, não se submetem a tais condições. O mesmo não ocorre, por exemplo, com ['kôj.tu] ('biscoito'), ['gux.tsi] ('iogurte') e ['trê.la] ('estrela'), que apresentam diferentes realizações na palavra reduplicada. Podemos admitir, portanto, as seguintes condições de boa-formação silábica: 
(25) a. sílabas devem ter a posição de ataque preenchida;

b. ataques devem ser simples;

c. sílabas não-finais são sempre abertas.

As condições (a) e (b) regulam o formato do onset, que deve aparecer sempre e não pode ser complexo. A restrição em (c) condiciona a presença de codas (elementos travadores de sílabas). Assim, sílabas fechadas (não terminadas em vogal) só são permitidas na margem direita da palavra: codas internas são proibidas. Essa condição explica a manutenção da semivogal em 'pepéu’ (<< ‘chapéu’) e a falta desse segmento em ‘cocoto’ (<< ‘biscoito'). Ao mesmo tempo em que garantem estruturas não-marcadas, tais condições levam a forma reduplicada a destoar da palavra-fonte.

As estruturas simplificadas passam a funcionar como bases para o processo de reduplicação. No fenômeno em análise, repetimos, o reduplicante é do tipo prefixo e copia, da esquerda para a direita, a primeira sequência CV da base encurtada. Desse modo, como o reduplicante tem o formato $\mathrm{CV}$ e as bases tendem a ser constituídas de duas sílabas (['pê.ta], de 'chupeta', e ['né.ka], de 'boneca') ou, menos frequentemente, de uma única sílaba com coda (['péw], de 'chapéu', e ['miw], de 'dormiu'), sendo raros os monossílabos leves (['lé], de 'picolé', e ['gu], de 'angu'), a reduplicação em análise quase nunca é total. Nos dissílabos, o prefixo é sempre igual à primeira sílaba da base; nos monossílabos sem coda, o reduplicante é uma cópia perfeita da base. Nos monossílabos travados, no entanto, o reduplicante é infiel à base, uma vez que a coda não é copiada, por não caber no molde CV do prefixo reduplicativo. Como se vê, o processo é altamente regular, considerando-se que atua na fronteira da morfologia com a fonologia, não sendo, de modo algum, arbitrário ou assistemático.

Em relação aos hipocorísticos, nomes próprios encurtados afetivamente, a seguinte lista de formas reduplicadas é bastante extensa e em (26), a seguir, damos uma pequena amostra de hipocorísticos reduplicados. Adotamos, aqui, a definição de hipocorização proposta por Gonçalves (2004: 08): “processo morfológico pelo qual antropônimos são encurtados afetivamente, resultando numa forma diminuta que mantém identidade com o prenome ou com o sobrenome original".

(26) Cacá $(<$ Carlos $)$

Dudu $(<$ Edu $<$ Eduardo $)$

Gegê $(<$ Getúlio)

Zezé (< José)

Juju $(<$ Juliana $)$

\author{
Bebel ( $<$ Isabel) \\ Teteu ( $<$ Mateus) \\ Quequel $(<$ Raquel) \\ Ceceu $(<$ Alceu $)$ \\ Lalau $(<$ Nicolau $)$
}


Lima, Thami da Silva \& Gonçalves (2010) analisaram a reduplicação nesse tipo de formação e concluíram haver severas restrições sobre o reduplicante, que não pode se iniciar por vogal, nem apresentar coda, tendo sempre o formato $\mathrm{CV}$, independente de ser aproveitada a sílaba inicial ('Cacá' < 'Carlos'), a primeira com ataque ('Dudu' < 'Edu' < 'Eduardo') ou a tônica ('Zezé' < 'José'). Observa-se, pelos dados em (26), que a reduplicação pode ser total ('Lulu' <<'Luíza') ou parcial ('Bebel' <<'Isabel'), mas tem sempre o formato CV e é do tipo prefixal. Do ponto de vista do processo de reduplicação, portanto, a regularidade é absoluta.

\section{PALAVRAS FINAIS}

Podemos concluir que a reduplicação é um fenômeno que abrange os dois principais processos morfológicos da língua: a derivação e a composição. Além disso, é um típico fenômeno de interface morfologia-fonologia, já que os reduplicantes são desprovidos de conteúdo segmental, manifestando-se através de uma operação de cópia. Resumindo, em português, o fenômeno se manifesta nas seguintes situações:

(a) reduplicação em início de palavra, utilizada, sobretudo,

i. em relações de parentesco: 'papai', 'mamãe', 'titio', 'vovó', 'vovô';

ii. em hipocorísticos: 'Dedé', 'Bebel', 'Lulu', 'Teteu';

iii. no baby-talk: 'pepeta', 'bebelo', 'pipito', 'neneca', 'dedera'.

(b) reduplicação no final de palavra, quase sempre vinculada à expressão da intensidade: 'bololô', 'chororó', 'bafafá', 'trelelê', 'melelê';

(c) reduplicação de base verbal: 'pega-pega', 'mata-mata', 'quebra-quebra'.

\section{REFERÊNCIAS}

ALBUQUERQUE, L. R.; GONÇALVES, C. A. V. Análise da reduplicação em dados de aquisição: uma abordagem otimalista. In: VIII Congresso Nacional de Filologia e Lingüística, 2005, Rio de Janeiro. Questões de morfossintaxe. Rio de Janeiro: CiFeFil, 2004, v. 8, p. 45 53.

ARAÚJO, G. Processos morfológicos marginais no português brasileiro: truncamento e reduplicação. Comunicação apresentada no Colóquio Acento em Português. Campinas: UNICAMP, 2000, mimeo.

AUGÉ, M. Les domaines de la parenté. Paris: François Maspero, 1975.

BASÍLIO, M. Teoria lexical. São Paulo: Ática, 1987. 
BRINTON, L.; TRAUGOTT, E. C. Lexicalization and Language Change. Cambridge, UK: Cambridge University Press, 2005.

COUTO, Hildo Honório do. A reduplicação em português. Lusorama. 1999.

COUTO, Hildo Honório do. A reduplicação nos crioulos portugueses. In: D'ANDRADE, Ernesto; MOTA, Maria A.; PEREIRA, Dulce (Org.). Crioulos de base lexical portuguesa. Lisboa: Associação Portuguesa de Lingüística, p. 61-80, 2000.

CRYSTAL, David. A Dictionary of Linguistics and Phonetics. $4^{\mathrm{a}}$ ed., London: Copyright, 1997.

CUNHA, C. F.; CINTRA, L. Nova gramática do português contemporâneo. $2^{\mathrm{a}}$ ed. Rio de Janeiro: Nova Fronteira, 1985.

GARCIA, D. La oralidad en el discurso narrativo escrito de adolescentes mexicanos : el fenómeno linguístico de la repetición. México: Universidad Nacional Autónoma de México, 1996.

GONÇALVES, C. A. V. A morfologia autossegmental e o tratamento não-linear da reduplicação. In: MARÇALO, M. J.; LIMA-HERNANDES, M. C.; ESTEVES, E.; FONSECA, M. C.; VILELA, A. L.; GONÇALVES, O.; SILVA, A. (Ed.). Língua portuguesa: ultrapassar fronteiras, juntar culturas. Évora: Universidade de Évora, p. 35-49, 2010.

GONÇALVES, C. A. V. Retrospectiva dos estudos em Morfologia Prosódica: das circunscrições e regras à abordagem por ranking de restrições. Alfa (ILCSE/UNESP), v. 53, p. 195-221, 2009.

GONÇALVES, C. A. V. Processos morfológicos não-concatenativos: formato prosódico e latitude funcional. Alfa (ILCSE/UNESP), Araraquara, v. 48, n. 2, p. 30-66, 2004.

GUILBERT, L. Fondements lexicologiques du dictionnaire. In: ---. Grand Larousse de la langue française en six volumes (p. IX-LXXXI). Paris: Larousse, 1971.

KEY, H. Some semantic functions of reduplication in various languages. Anthropological linguistics, New York, 2 (1): 23-45, 1965.

LIMA, B. C.; SILVA, H. T.; GONÇALVES, C. A. V. A hipocorização no português do Brasil: análise por padrões gerais de formação. In: GONÇALVES, Carlos Alexandre et al. (Org.). Otimalidade em foco: morfologia e fonologia do português. 1 ed. Rio de Janeiro: Publit, 2009, p. 115-151.

KIYOMI, S. A new approach to reduplication: a semantic study of noun and verb reduplication in the Malayo-Polinesian languages. Linguistics, Massachusetts, 23 (1): 234-257, 1995.

MARANTZ, A. Reduplication. Linguistic Inquiry, MA: MIT, 21 (1): 435-483, 1982.

THORNTON. A. M. Italian verb-verb reduplicative action nouns. Italy: Facoltà di Lettere e Filosofia. 2008. 
VIALLI, L. D. A reduplicação em língua portuguesa: análise do baby-talk. In: GONÇALVES, C. A. V. et al. Otimalidade em foco: morfologia e fonologia do português. Rio de Janeiro: Publit, 2011.

VIALLI, L. A. D. Reduplicação de base verbal: uma análise pela morfologia construcional. Tese (Doutorado em Letras Vernáculas). Rio de Janeiro: UFRJ, 2013.

VIALLI, L. D. Reduplicação em baby-talk: uma análise morfo-prosódica. Dissertação (Mestrado): Faculdade de Letras, Universidade Federal do Rio de Janeiro. Rio de Janeiro, 2008.

VILALVA, A.; GONÇALVES, C. A. V (no prelo). The phonology and morphology of Wordformation. In: WETZELS, L. et al. (Org.). The Handbook of Portuguese Linguistics. Amsterdam: John Benjamins Publishing Co.

VILELA, M. Estruturas léxicas do português. Coimbra, Almedina, 1979.

WIERZBICKA, A. Italian reduplication: cross-cultural pragmatics and illocucionary semantics. Linguistics, 24 (2), 287-315, 1986.

Recebido em 6 de março de 2015.

Aceito em 12 de maio de 2015. 
